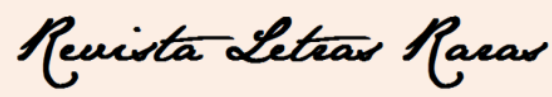

ISSN: 2317-2347 - Vol. 5, Ano 5, № 2 - 2016

\title{
Leituras sobre África: Aya de Yopougon de Marguerite Abouet no ensino da leitura e da cultura africana no ensino fundamental - EJ $\mathbf{J A}^{\mathbf{1}}$
}

João Vicente ${ }^{*}$

Maria da Glória Magalhães dos Reis

Resumo: O presente artigo apresenta uma pesquisa realizada com o objetivo de promover a leitura de obras de ficção em sala de aula e aplicação da Lei ${ }^{\circ} 10.639 / 2003$ que trata da obrigatoriedade do ensino da cultura e história africanas nas escolas públicas brasileiras. A metodologia que foi aplicada é baseada em pesquisa-ação e envolveu a elaboração de uma orientação didático reflexiva (ODR) que foi aplicada em turmas de $6^{\circ}$ do Ensino Fundamental, em regime de Educação de Jovens e Adultos no turno noturno em região periférica do Distrito Federal. A obra lida foi Aya de Yopougon de Marguerite Abouet, autora contemporânea de origem marfinense. Trata-se de livro em quadrinhos, publicado originalmente em francês, traduzido para o português e adotado no Programa Nacional Biblioteca na Escola desde 2012. Foram propostas atividades envolvendo a leitura e os discursos produzidos foram analisados e nota-se que a atividade foi profícua para introdução das/dos estudantes na cultura africana e no desenvolvimento da leitura literária.

Palavras-chave: Educação. Leitura. Diversidade Cultural. Direitos Humanos.

\section{Readings about Africa: Aya de Yopougon by Marguerite Abouet to teach reading and african culture in elementary school}

\begin{abstract}
This article presents a research with the aim of promoting reading fiction in the classroom and the application of Law 10.639/2003 which deals with the obligation of teaching the African culture and African history in Brazilian public schools. The methodology is based on researc-action and involved the development of a reflective teaching guidance to be applied in 6 classes of elementary school, in youth and adult education system the night shift in the peripheral region of the Federal District. The work was read Aya of Yopougon Marguerite Abouet, contemporary author of Ivorian origin. It is comic book, originally published in French, translated into Portuguese and adopted the National Programme School Library since 2012. It was proposed activities involving reading and produced reports were analyzed and it is noted that the activity was profitable for introduction of / students in African culture and development of literary reading.
\end{abstract}

Keywords: Education. Reading. Cultural Diversity. Human Rights.

\footnotetext{
${ }^{1}$ Este artigo foi escrito a partir do trabalho de conclusão de curso de Especialização em Educação em e para os Direitos Humanos, no contexto da Diversidade Cultural concluído pelo primeiro autor em 2015 no Instituto de Psicologia da Universidade de Brasília.
}

*Universidade de Brasília (UnB) e Secretaria de Educação do Distrito Federal (SEDF), Brasília. Doutorando em Literatura pela UnB. Professor da SEDF. E-mail: joaovicente.br@gmail.com

${ }^{* *}$ Universidade de Brasília (UnB), Brasília. Doutora em Letras (Estudos linguísticos, literários e tradutológicos) pela USP. Professora adjunta IV. UnB - Pós-Lit. E-mail: gloriamagalhaes@gmail.com

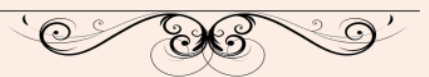




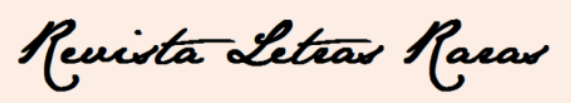

ISSN: 2317-2347 - Vol. 5, Ano 5, № 2 - 2016

\section{Introdução}

A Lei $n^{\circ} 10.639 / 2003$ (posteriormente modificada pela Lei $n^{\circ} 11.645$, de 10/03/2008) tornou obrigatório o ensino da cultura e história da África nas escolas, no entanto, até os dias atuais nos deparamos com diversas questões relacionadas à sua implementação de fato. Tais questões vão desde o despreparo dos profissionais para atuação no tema específico até à própria dificuldade no desenvolvimento de aulas de leitura e literatura nas escolas.

Por muitos anos a cultura africana não teve na educação brasileira a devida atenção. $\mathrm{Na}$ maioria das vezes o ensino se restringe a imagens de pessoas escravizadas, sendo tratadas de maneira naturalizada e sempre do ponto de vista eurocêntrico. Basta passar a vista pelos livros didáticos e veremos os espaços que foram reservados aos brasileiros descendentes de africanos e aos africanos nesses livros. Esse silenciamento é também efeito de muitos outros aspectos da sociedade, a escola é um espelho dessa sociedade, ao mesmo tempo em que a reforça veemente

Na cultura brasileira, atualmente mesmo na música ou dança pouco temos notado ou falado sobre nossas heranças africanas. Ao contrário, o Brasil tem se tornado "exportador" de seus subprodutos da cultura de massa (televisão, cinema, música), para os países africanos. Aliás, esses países têm sofrido com a entrada da cultura de massa e mundialização crescente, que achata culturas e apaga os relevos tão importantes do continente mais antigamente povoado.

Pensando nessas visões estereotipadas a respeito das culturas africanas, seja historicamente estagnada na fase da escravidão negra ou atualmente baseada em recortes extremos da imprensa internacional, notamos que seria preciso aportar aos jovens novos elementos a respeito da cultura africana. Quanto às visões disseminadas atualmente, não as julgamos superadas, a escravidão é um fato histórico que reverbera com força imensa até os nossos dias, e as catástrofes noticiadas são por si testemunhas de anos de exploração européia, mas é preciso narrar diversos aspectos, para sair do maniqueísmo e dar sentidos e tensão à narrativa. Isso porque, se acreditamos que é necessário reelabora o pensamento a respeito do povo negro no Brasil, e para que comece a fazer sentido para os jovens a ideia de orgulho negro, é necessário fornecer elementos para a construção dessa narrativa.

A Lei $n^{\circ} 10.639 / 2003$ dispõe sobre os seguintes aspectos: a obrigatoriedade do estudo da História da África e dos Africanos de maneira ampla, que deverá ocorrer no ensino 


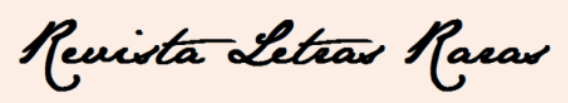

ISSN: 2317-2347 - Vol. 5, Ano 5, № 2 - 2016

fundamental e médio, na educação pública ou particular, e em especial quanto às artes, literatura e história. Vários artigos relatam a dificuldade dos professores em aplicar essa lei, seja por desconhecimento dela, por falta de formação em seus cursos ou continuada ou por falta de material didático.

Nesse sentido, nada melhor que a literatura vista sua universalidade e sua força estética. $\mathrm{O}$ gênero escolhido, a história em quadrinhos, tem ainda outros elementos de forte apelo aos jovens, alguns relacionados à linguagem não verbal (cores, formas, estrutura, dinâmica) e, até mesmo certa dramaticidade, o que facilita a leitura nos níveis mais básicos. Além disso, soma-se o fato de que a atividade proposta foi realizada em aulas de língua portuguesa do sexto ano do Ensino Fundamental Noturno em uma sala de Educação de Jovens e Adultos - EJA.

\section{Aya de Yopougon e novas leituras sobre África a partir da literatura}

A obra Aya de Yopougon foi escrita pela marfinense Marguerite Abouet e desenhada pelo francês Clément Oubrerie. A tradução para a Língua Portuguesa foi realizada por Julia da Rosa Simões e integra o Programa Nacional Biblioteca na Escola (PNBE) desde 2012. Tratase uma história em quadrinhos editada primeiramente em francês até o volume 6, mas já traduzida em português até o número 3. De acordo com a Lei nº 10.639/2003 são prioritárias na sua aplicação as disciplinas de educação artística, a literatura e a História. A história em quadrinhos foi assim adotada, pois entendemos a literatura no seu sentido mais amplo possível: como a produção estética da língua, que molda os elementos da vida real em ficção. Aya de Yopougon é escrito por uma autora marfinense que tem como objetivo declarado, como dito anteriormente, mudar as visões estereotipadas a respeito de África no mundo. Ela busca demonstrar, em relato de experiências autobiográficas que se mesclam à ficção, como se passa a vida de três jovens garotas na Costa do Marfim da década de 1970. A escolha se deu com base em vários fatores, entre eles o predominante foi o fato de a narrativa toda estar baseada em Yopougon, uma cidade da Costa do Marfim e ter como personagens centrais três adolescentes negras em conflitos a respeito da vida, dos estudos, dos amores, isto é, dramas adolescentes como quaisquer outros no mundo. A obra lida em sala de aula é por si, uma proposta de trabalho com a diversidade. Primeiramente, porque entendemos literatura em um

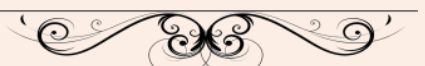




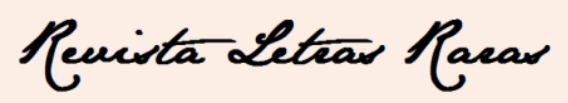

ISSN: 2317-2347 - Vol. 5, Ano 5, № 2 - 2016

sentido amplo como afirma Candido (1995, p. 74) "todas as criações de toque poético, ficcional ou dramático em todos os níveis de uma sociedade, em todos os tipos de cultura", trata-se portanto de permitir-se extrapolar o cânone da literatura e englobar também autores e obras que não estão propriamente nas linhas de frente de estudos literários. O grupo de personagens centrais poderia gerar empatia nos estudantes já que têm mesma faixa etária e passam pelos mesmos tipos de questões na vida. Chama a atenção na obra a apresentação da escritora Anna Gavalda "esqueça tudo que você ouviu sobre a África. Este livro vai lhe dar uma outra visão". Seria possível uma obra literária atuar como catalisadora de novas leituras sobre África?

A história em quadrinhos toda baseada em situações cotidianas de um país africano surpreende os estudantes, que mesmo sendo em sua maioria afrodescendentes, demonstram surpresa ao ver um livro em que todos os personagens são negros. Ao contrário, como já observamos, nenhuma estupefação é notada se todos os personagens de um livro, filme, ou novela são brancos. Nota-se que há necessidade de elaboração de novas narrativas para conscientização das pessoas em geral a respeito das questões étnico-raciais, fortalecimento da luta pelos direitos humanos do povo negro no Brasil, aumento do respeito à diversidade cultural e melhorias na forma de lidar com as diferenças, a leitura coletiva de Aya de Yopougon poderia ser um instrumento valoroso para tanto.

O trabalho com um gênero específico, como é o caso da história em quadrinhos ou romance gráfico permite estabelecer como base toda a teoria da leitura e aprendizado de língua materna que tem como base os gêneros textuais, primários ou secundários. Além do exposto acima, o gênero escolhido permitiu uma leitura em grupo e os exercícios de jogos de oralidade propostas, propiciando assim a experienciação da leitura. $\mathrm{O}$ gênero conta ainda com o forte recurso imagético que promove a compreensão e a leitura dos estudantes que ainda estão em fase de desenvolvimento, visto que são alunos de EJA no início do segundo seguimento do ensino fundamental.

\section{Literatura e lei}

A Lei $n^{\circ}$ 10.639/2003 que busca dar ênfase à história e cultura afrobrasileira, ao mesmo tempo indica que seus conteúdos devem ser ministrados, em especial, na área da

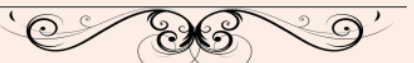




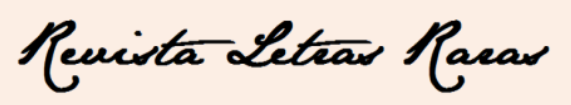

ISSN: 2317-2347 - Vol. 5, Ano 5, № 2 - 2016

Educação Artística, Literatura e História Brasileira, ou seja, indica caminhos para a atuação dos educadores. É necessário refletir um pouco sobre o papel social das leis e seu lugar na cultura. É interessante notar como as leis têm um papel importante na transferência da importância da palavra oral para a palavra escrita. Na nossa sociedade contemporânea, quantas vezes não nos perguntamos se certos comportamentos desejados não deveriam partir do bom senso natural das pessoas e não de leis redigidas, votadas e promulgadas. No caso da lei $\mathrm{n}^{\mathrm{o}} 10.639 / 2003$, talvez pudéssemos nos questionar por que impor via de lei o ensino da cultura e história afrobrasileira, se ela é a nossa própria história. A resposta a esse possível questionamento nos é dada a partir dos fatos e do desenrolar da história que nos mostrou que a lei era necessária, como nos mostra o próprio texto da lei que expomos a seguir:

Art. 26-A. Nos estabelecimentos de ensino fundamental e médio, oficiais e particulares, torna-se obrigatório o ensino sobre História e Cultura AfroBrasileira.

$\S 1$ o O conteúdo programático a que se refere o caput deste artigo incluirá o estudo da História da África e dos Africanos, a luta dos negros no Brasil, a cultura negra brasileira e o negro na formação da sociedade nacional, resgatando a contribuição do povo negro nas áreas social, econômica e política pertinentes à História do Brasil.

§ 2o Os conteúdos referentes à História e Cultura Afro-Brasileira serão ministrados no âmbito de todo o currículo escolar, em especial nas áreas de Educação Artística e de Literatura e História Brasileiras.

"Art. 79-B. O calendário escolar incluirá o dia 20 de novembro como 'Dia Nacional da Consciência Negra'." (BRASIL, 2003)

Sabemos que as ações de leis têm seu peso e são necessárias como desencadeadoras de melhorias futuras na sociedade, uma sociedade que sem uma lei ainda não tinha entendido que precisa ensinar e estudar sua própria história. Uma mesma sociedade, aliás, que tem negligenciado mais uma entre tantas de suas leis. De acordo com Fernandes (2005) a implementação da lei $n^{\circ}$ 10.639/2003 "possibilitou a ruptura do modelo eurocêntrico no ensino e a construção de uma educação multicultural na escola brasileira", pois segundo esse mesmo autor "uma análise mais acurada da história das instituições educacionais em nosso país, por meio dos currículos, programas de ensino e livros didáticos mostra uma preponderância da cultura dita 'superior e civilizada', de matriz européia". Não há dúvidas de que a lei abre caminhos para essa ruptura, mas quem a faz de fato são os atores, os cidadãos em geral, e para isso, não necessárias ações de intervenção diárias. 


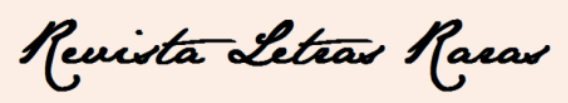

ISSN: 2317-2347 - Vol. 5, Ano 5, № 2 - 2016

Em sua ampla revisão sobre o racismo e seu combate nos livros didáticos Rosemberg et al. (2003) destaca que a produção brasileira a esse respeito na época da publicação do trabalho era incipiente, o que quer dizer que vivemos uma época em que crescem os interesses pela questão do racismo, por exemplo, com a aprovação da lei em estudo. Essa autora, assim como Fernandes (2005) demonstram preocupação em relação à formação dos professores para aplicação das leis nas escolas, o que é legítimo, pois nós licenciados sabemos que na maioria das vezes não recebemos essa formação. No entanto, existem muitas maneiras de se buscar essa formação e isso não será um fator que inviabilizará a implantação a contento de uma lei tão relevante. Outra preocupação é com a qualidade do material didático. Foi nesse sentido que sentimos a necessidade de uma leitura literária, de uma obra como Aya de Yopougon, pois os livros didáticos de fato não suprem esse conteúdo, aliás nem sequer o abordam ao longe. É preciso trazer para a sala de aula materiais que valorizem um multiculturalismo crítico a pluralidade cultural (CANEN, 2013, p. 50).

Conforme afirma Dias (2005) as condições escolares no Brasil melhoraram, mas as diferenças de oportunidades entre crianças brancas e não brancas persistem, portanto "o que seguramente pode ser afirmado é que raça ainda é um problema a ser discutido", ao contrário do que muitos tentam afirmar. A própria aprovação da lei em 2003 vem a público nos dizer que há uma questão a ser discutida, que temos questões da população negra e porque não dizer, da população em geral, pois no âmago da questão trata-se de nossa diversidade cultural que não caminham bem. Como apontam diversos autores, o fato de não ter havido um sistema de separação oficial como o apartheid sul-africano ou estadunidense dá ao Brasil a ilusão de harmonia na miscigenação.

Educar nos ambientes diversos é sem dúvida muito mais difícil, poderíamos nos questionar se a diversidade cultural cresceu de fato ou se simplesmente a percepção é que mudou. No passado, a opção seria sempre de buscar anular ou no mínimo diminuir as diferenças culturais tentando amenizar as diferenças dentro do ambiente escolar. Atualmente temos a tarefa de buscar mais respeito e convivência dentro e fora das escolas. Os desafios são maiores, mas os ganhos também o podem ser. É nesse contexto que "as buscas de construção de processos educativos culturalmente referenciados se intensificam" (OLIVEIRA; CANDAU, 2010. p. 16). Para as autoras citadas é preciso ir além, é necessário “desconstruir o mito da democracia racial; adotar estratégias pedagógicas de valorização da diferença; reforçar a luta antirracista e questionar as relações étnicorraciais baseadas em preconceitos e 


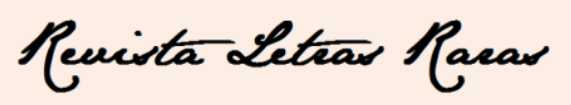

ISSN: 2317-2347 - Vol. 5, Ano 5, № 2 - 2016

comportamentos discriminatórios". A reflexão dessas mesmas autoras tem uma excelente conclusão que consideramos válido citar também para encerrar esta parte a respeito da lei $\mathrm{n}^{\circ}$ 10.639/2003:

por fim, podemos considerar que a lei $10.639 / 03$ pode criar condições, dependendo das perspectivas adotadas pelos sujeitos envolvidos, para o estabelecimento, no contexto educacional brasileiro, de conflitos, confrontos e negociações epistêmicas, pondo em evidência a diferença através do pensamento crítico de fronteira, [...], pois essa legislação permite a visibilidade de outras lógicas históricas, diferentes da lógica dominante eurocêntrica, além de pôr em debate a descolonização epistêmica. (OLIVEIRA; CANDAU, 2010. p. 38)

Essa conclusão demonstra a importância da criação e promulgação da lei, mas ao mesmo tempo dá a devida importância aos "sujeitos envolvidos", em outras palavras, sabemos que não basta o decreto, há que existir vontade do agente educacional para que ela se cumpra e principalmente para que gere os efeitos desejados. E esses efeitos vão muito além de simplesmente esclarecer um pouco mais a população, espera-se mudar a percepção da população brasileira em relação às suas origens, suas histórias, fazer notar a perspectiva eurocêntrica e a possibilidade de narrativas outras a serem criadas e contadas.

\section{A diversidade cultural e a prática de leitura coletiva de Aya de Yopougon}

A diversidade cultural deve ser valorizada no ambiente escolar, pois este é um ambiente naturalmente diverso, mas com tendências a certa padronização nos comportamentos, nas visões, nas leituras de mundo, por seguir modelos homogeneizantes. $\mathrm{Na}$ literatura, a hegemonia de gêneros e autores canônicos reflete a exclusão da diversidade no ambiente escolar. Nessas construções de novas posições dos sujeitos, a exclusão acaba por ser praticada (NASCIMENTO; DELMONDEZ, 2014). E a tomada da leitura de textos com temáticas da cultura africana sob nova perspectiva pode funcionar como um elemento de valorização da diversidade e de ação que ajude a romper com modelos homogeneizantes e que contribuem para o acontecimento de reações negativas à diversidade, como "racismo, 


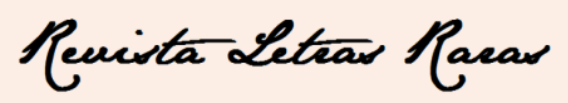

ISSN: 2317-2347 - Vol. 5, Ano 5, № 2 - 2016

sexismo, homofobia, classismo, etarismo, intolerância religiosa, morfofobias" (NASCIMENTO; DELMONDEZ, 2014).

A prática de leitura coletiva, ao invés da leitura silenciosa e individual, pode a nosso ver, promover o que dispõe Nascimento e Demondez (2014): “as experiências subjetivas e coletivas se interconectam mutuamente, pois relacionam as narrativas de diferença mediante processos coletivos compartilhados". Aya de Yopougon (2011) de Marguerite Abouet e Clément Oubrerie é uma história em quadrinhos que tem temática completamente diversa dos produtos de massa como heróis, e traz como protagonistas três jovens garotas africanas que tomam a frente da história em suas ações. Elas são apresentadas de maneira realista, sem grande "romantização" da adolescência ou da vida cotidiana; enfrentam suas realidades dentro de suas possibilidades. Dessa forma, acreditamos que uma possível identificação foi mais facilmente promovida do que com autores canônicos da literatura ou quadrinhos já assimilados pela cultura de massa.

As rodas de leitura são espaços de possível construção de subjetividade (KASTRUP, 2005), daí a importância de utilizá-la na pesquisa em educação. Os dados sob a análise de Galeno Amorim (2008) a respeito da pesquisa Retratos da Leitura no Brasil mostram algumas tendências do leitor brasileiro, dentre elas podemos destacar: clericalização do leitor visto que a bíblia é de longe o livro mais lido; infantilização do leitor, dos trinta livros mais lidos treze são infantis; restrição aos livros recomendados na escola; resposta imediata à incitação da industria editorial e mínima leitura em língua estrangeira. Somaríamos à essa análise a contradição entre a informação sobre o gosto da leitura e o número de livros efetivamente lidos. Os dados da pesquisa são de natureza prioritariamente quantitativa, mas já nos dão um panorama pouco animador no cenário atual da leitura no Brasil ${ }^{2}$. Nesse quadro, a afirmação de Paulo Freire de 1993 torna-se ainda atual: “é urgente que a questão da leitura e da escrita seja vista enfaticamente sob o ângulo da luta política a que a compreensão científica do problema traz sua compreensão" (FREIRE, 2011, p. 17).

\footnotetext{
2 De acordo com a pesquisa citada brasileiro lê 4,7 livros por por ano, para esta média são considerados os valores para estudantes $(7,2)$ e não-estudantes $(3,4)$. A maioria dos livros lidos é por recomendação escolar. 0 autor apresenta interessante reflexão sobre os dados: "embora 64\% dos entrevistados afirmem gostar de ler (muito,27\%; um pouco, 37\%), e ler prioritariamente por prazer, e até reler (30\%) certas obras, o que revelaria o fato de $40 \%$ dos entrevistados alfabetizados não conseguirem citar um livro que estejam lendo ou tenham lido: memória fraca? Desimportância da informação, mesmo o item título ter sido indicado como o segundo mais importante, na escolha do livro para leitura e para compra? (AMORIM, 2008, p.52).
} 


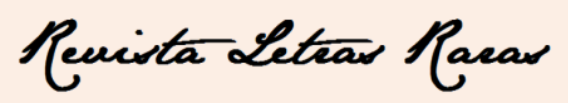

ISSN: 2317-2347 - Vol. 5, Ano 5, № 2 - 2016

Regina Zilberman, (1991, p. 9) já considerava que o nível de leitura da população brasileira é baixo, seja pelo nível baixo de consumo de material impresso, "pelo reduzido poder aquisitivo, ausência de política cultural contínua e eficiente e a influência cada vez maior dos meios audiovisuais de comunicação de massa". Nesses últimos anos, não muita coisa mudou, exceto esse último fator que se acentuou fortemente. Sem que o letramento tenha de fato se universalizado no Brasil, ou como afirma Zilberman sem que "tenhamos experimentado os fenômenos de escolarização coletiva" (1991, p. 9) as mídias eletrônicas tomaram um espaço imenso na sociedade.

Mas se os jovens e adultos estão inseridos nessa sociedade de mídias eletrônicas, interagem nela, porque ainda deveríamos reivindicar a leitura ou ao ato de ler, posto que aparentemente passa-se bem sem ele? Exatamente, porque isso se passa apenas na aparência, "o ato de ler qualifica-se como uma prática indispensável para o posicionamento correto e consciente do indivíduo perante o real" (ZILBERMAN, 1991, p. 17). O texto literário, na medida em que cria realidades completas e paralelas à do leitor contribui para o entendimento da própria realidade vivida. No entanto, é preciso sempre lembrar que "a leitura do mundo precede a leitura da palavra" (FREIRE, 2011, p. 19), tal afirmação é importante para nosso posicionamento como docentes, para a tomada de partida em atividades em sala de aula. É claro, que quando a leitura da palavra acontece de maneira efetiva ela irá começar a modificar as leituras que temos do mundo.

O "fracasso" do leitor é consequentemente o fracasso da educação em si, pois como já afirmamos anteriormente esses são processos estreitamente ligados. Não é possível que um educando que não lê bem se desenvolva bem em outros aspectos de sua vida escolar, conforme afirma Zilberman:

o ingresso do indivíduo na vida comunitária coincide com o momento em que ele começa a freqüentar a escola e aprender a ler. Ensino e leitura são atividades que, também sob esse aspecto, se confundem, constituindo-se, desde então, no fundamento do processo de socialização do indivíduo (ZILBERMAN, 1991, p. 18)

Com o ingresso da pessoa na sociedade por meio da palavra, ele irá se modificar e também terá suas chances de modificar o mundo, como afirma Freire (2011, p. 40) "a educação modela as almas e recria os corações, ela é a alavanca das mudanças sociais". Se 


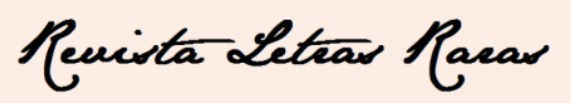

ISSN: 2317-2347 - Vol. 5, Ano 5, № 2 - 2016

tomamos a leitura como a principal via da educação podemos afirmar que é a leitura a grande mola de mudanças sociais.

Ao longo da história, os papéis dados ao texto literário em sala de aula foram se alterando, ganhando e perdendo espaço, mas um deles quase sempre permanece que é o de exemplo da norma culta. O uso da literatura como matéria educativa, de fato, antecede a existência formal da escola (COSSON, 2014b, p. 20). De fato, em recente estudo analisando livros didáticos distribuídos pelo Fundo Nacional do Livro Didático e utilizados no ensino médio brasileiro Diniz (2012, p. 119) observou que 18\% dos textos literários dos livros estão em capítulos da área de linguística, a maioria em trechos destinados à gramática, o que a autora chamou de uso como "pré-texto". Segundo Zilberman (1991, p. 135) o professor de literatura no ensino médio se vê diante de apenas duas possibilidades: optar por uma “concepção humanista" ou ceder ao trabalho de preparar para o vestibular. Uma maneira de abordar dialogicamente o texto literário em sala de aula é a apontada por Antonio Candido (1985, p. 5) quando sugere ao "ao professor e ao estudante maneiras possíveis de trabalhar o texto", mas:

partindo da noção de que cada um requer tratamento adequado à sua natureza, embora com base em pressupostos teóricos comuns. Um destes pressupostos é que os significados são complexos e oscilantes. Outro, que o texto é uma espécie de fórmula, onde o autor combina consciente e inconscientemente elementos de vário tipo. (CANDIDO, 1985, p. 5)

Tratada como pré-texto nos livros didáticos a literatura parece ser apenas um ornamento da língua, um apêndice, mas ela "participa da própria constituição da língua, contribui para lhe conferir qualidade de língua, estatuto de língua" (MAINGUENEAU, 2006, p.197). Esse mesmo autor afirma que a literatura desempenha um caráter capital no processo de delimitação das línguas, segundo ele para que haja uma língua é necessário que exista um corpus literário. Fica-nos claro, portanto, que o ensino da literatura, e especialmente da literatura africana e afrobrasileira, não pode ser deixado de lado, nem tampouco tratado como apêndice do ensino da gramática, dada a indissociabilidade da língua e da literatura.

A questão do ensino torna-se mais importante, pois, ainda de acordo com Candido (1995, p. 174) "vista deste modo a literatura aparece claramente como manifestação universal de todos os homens em todos os tempos". É na arte literária, por exemplo, que podemos 


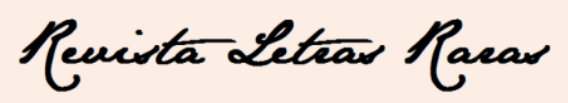

ISSN: 2317-2347 - Vol. 5, Ano 5, № 2 - 2016

buscar a compreensão do outro o que requer a compreensão da própria complexidade humana, mesmo sendo ficção, com eles podemos aprender "as maiores lições da vida" (MORIN, 2012. p. 88). Portanto, a literatura não poderia perder seu espaço, ou vê-lo tornar-se "escasso" na sociedade, na escola, na imprensa ou nos lazeres como afirma Antoine Compagnon (2009, p. 21). Nesse cenário, não causa estranheza, portanto, afirmar nesse momento, que a "o lugar da literatura na escola parece enfrentar um de seus momentos mais difíceis" (COSSON, 2014b, p. 20). Nesse aspecto, a lei $\mathrm{n}^{\circ} 10.639 / 2003$ é clara a respeito da ênfase a ser dada nas artes e na literatura para o ensino da história e cultura afrobrasileira.

Se a literatura vem perdendo espaços na sociedade como afirma Compagnon, ela o perde, dentre outros, para as mídias eletrônicas de massa (filmes, telenovelas e outros artefatos), inclusive que geram produtos transmutados em literatura e mesmo para livros "pasteurizados" e sem significado social, empurrados pela propaganda massiva da indústria. Mas quando nos deparamos com afirmações como as de Cosson (2014b, p. 17) em que considera que é "na leitura e na escritura do texto literário que encontramos o senso de nós mesmos e da comunidade a que pertencemos" e complementa afirmando que "a literatura nos diz o que somos e nos incentiva a desejar e expressar o mundo por nós mesmos", a que conclusões podemos chegar? Talvez estejamos vivendo um momento em que as sociedades e seus indivíduos não estejam mais buscando saber quem são, ou nem mesmo tenham esse desejo em si. Ou ainda, que os processos de alienação foram de tal forma eficientes que nem mesmo desejamos expressar o mundo por nós mesmos. Porém como educadores, nosso papel é a busca de fazer acreditar nessa possibilidade, por mais árdua que seja a tarefa. Existe mesmo o pressuposto de que ler é um ato solitário, portanto inadequado para a sala de aula (COSSON, 2014b, p. 27), porém, é uma premissa que considera apenas uma maneira de leitura, que não abarca outras tantas maneiras possíveis que não silenciosa. Para Cosson (2014b, p. 27), ao contrário da leitura e interpretação solitária “o bom leitor [...] é aquele que agencia com os textos os sentidos do mundo, compreendendo que a leitura é um concerto de muitas vozes e nunca um monólogo".

Diante desse momento da leitura em crise e da perda de espaço da literatura na educação cabe também pensar qual seria a abordagem mais adequada, em outras palavras refletir a respeito do letramento literário. Como vimos em muitas atividades escolares o texto literário é proposto apenas como um exemplo da norma culta ou base para realização de exercícios gramaticais. Por outro lado, existem também abordagens em que se afirma que o 


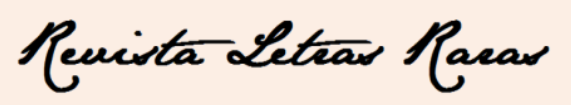

ISSN: 2317-2347 - Vol. 5, Ano 5, № 2 - 2016

importante é ler, seja o que for, seja como for, nesse caso leríamos a literatura na escola por mera fruição. Ambas são abordagens extremas e claramente problemáticas. Como bem define Cosson (2014b) “o letramento literário é uma prática social e, como tal, responsabilidade da escola", e continua:

a questão a ser enfrentada não é se a escola deve ou não escolarizar a literatura, [...], mas sim como fazer essa escolarização sem descaracterizála, sem transformá-la em um simulacro de si mesma que mais nega do que confirma seu poder de humanização (COSSON, 2014b, p. 23)

Para uma abordagem adequada da obra literária em sala de aula é importante ultrapassar a premissa de que se trata apenas de atividade solitária e silenciosa, mas perceber os múltiplos modos possíveis de se ler um texto literário, e com base nessa premissa buscamos a roda de leitura com jogos para ler Aya de Yopougon. A elaboração da orientação didático-reflexiva foi baseada no disposto por Dolz et. all. (2004) e na adaptação realizada pelo Grupo de Didática de Línguas e Literaturas Estrangeiras - GEDLLE ${ }^{3}$. Para Cosson (2014a, p. 72) quando lemos uma obra literária lemos o contexto, o texto e o intertexto, cada um deles em interações entre si e com o leitor e o autor. Tal ampliação da ideia de leitura, segundo Cosson (2014a, p. 97) é importante para "demonstrar que a leitura literária não tem apenas um caminho e que o diálogo pode ser efetivado por meio de várias atividades". Além disso, para alcançar realmente o letramento literário, "há necessidade de ir além da simples leitura do texto literário [...] é preciso fazer uma exploração da leitura e cabe à escola ensinar o aluno a fazer essa exploração" (BENVENUTI, 2012, p.87), de fato, cabe ao professor que é a representação subjetiva da instituição escola.

Procuramos, no desenvolver dessa atividade de intervenção, dar a devida atenção ao aspecto intuitivo por acreditarmos ser ele de suma importância para o desenvolvimento do leitor de obras literárias, como afirmam Santos e Spritzer (2012, p. 27) é preciso "despertar para a fantasia como matéria-prima da criação". Nesse processo, a atuação do educador pode perder parte do seu caráter castrador e assim a ajuda dele "não significa anular a criatividade e a sua responsabilidade na construção de linguagem escrita e na leitura desta linguagem" (FREIRE, 2011, p. 29).

\footnotetext{
${ }^{3}$ Disponível em: http://dgp.cnpq.br/dgp/espelhogrupo/0524323240846821
} 


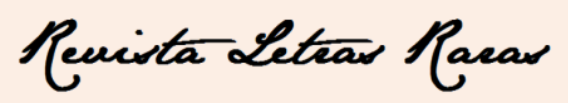

ISSN: 2317-2347 - Vol. 5, Ano 5, № 2 - 2016

Os trabalhos coletivos com os jogos podem funcionar como propulsores da liberação para leituras mais abrangentes e profícuas e compreensão mais acurada da história e cultura africana. Oliva (2003), afirma a respeito do ensino da História da África, mas pode ser também válido também para sua cultura:

as limitações transcendem - ao mesmo tempo em que se relacionam - os preconceitos existentes na sociedade brasileira, e se refletem, de um certo modo, no descaso da Academia, no despreparo de professores e na desatenção de editoras pelo tema (2003, p. 455).

A atividade de leitura em sala de aula envolveu três momentos: um pré-leitura, a leitura em si e um pós-leitura da obra Aya de Yopougon de Marguerite Abouet. Durante e após a sua realização o teor dos discursos apresentados pelos educandos foi registrado e analisado. Foi previsto um tempo de doze aulas de 45 minutos com uma turma de Língua Portuguesa do $6^{\circ}$ ano do Ensino Fundamental em região periférica do Distrito Federal. Os agentes da pesquisa são todos estudantes fora da idade esperada para o $6^{\circ}$ ano, uma vez que cursavam o $6^{\circ}$ ano em regime de EJA e que também têm seus primeiros contatos com a literatura e com história, e com muitas dificuldades em relação à leitura e escrita, ou grau de letramento ainda bastante incipiente. Eles/elas são homens e mulheres, entre 16 e 45 anos, alguns trabalham durante o dia e outros não. Foi utilizado como principal suporte o livro em quadrinhos acima citado.

Para sistematização dos resultados, fizemos no momento inicial apenas anotações sobre o debate e ideias gerais. Para dar início ao debate foi apresentada a questão "o que você conhece sobre África?" e ao longo das respostas espontâneas a turma foi tomando parte da conversa.

No processo intermediário, as/os estudantes elaboraram um texto que chamamos de depoimento, ele foi realizado após quatro aulas de leitura e as/os educandos ficaram livres para escrever sobre que aspecto lhes chamasse mais a atenção e também na quantidade de palavras que considerassem suficientes.

$\mathrm{Na}$ etapa final da atividade, ou seja, depois do término da leitura, as/os estudantes responderam a um questionário a respeito da leitura em si, da leitura coletiva, sobre a cultura africana em comparação à brasileira e sobre como suas visões sobre a cultura africana haviam sido afetadas pela leitura do livro em quadrinhos. Quanto ao questionário apresentado aos estudantes, eles também estiveram livres para não responder a uma ou mais questões.

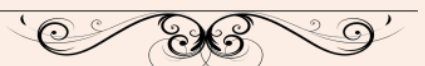




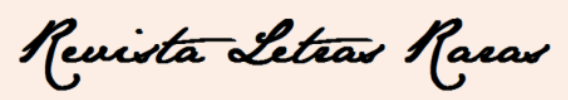

ISSN: 2317-2347 - Vol. 5, Ano 5, № 2 - 2016

Por fim, foi proposto às/aos estudantes elaborar um texto criativo ou desenho que tratasse da continuidade das narrativas de cada um dos personagens. Em todos esses instrumentos, buscamos discutir trechos que fossem mais significativos sobre a experiência e que apontassem para o cumprimento dos objetivos.

Realizado o debate, começamos a leitura do livro propriamente dito, com um jogo em que de pé, a cada vírgula o leitor deve fazer meia volta com o corpo e a cada ponto uma volta completa. Isso não apenas contribuiu para a desinibição, mas também melhorou a leitura, mostrando o tempo de cada pontuação. As atividades de cunho mais lúdico foram importantes para a liberação do corpo e do pensamento para a leitura. Após quatro aulas de leituras, os estudantes escreveram sobre suas impressões gerais, de forma livre, o que quisessem. Esses textos foram chamados "depoimentos", tomando como base a estratégia adotada por Reis (2008).

\section{Resultados da atividade de leitura}

A atividade de leitura gerou pelo menos quatro momentos em que os educandos apresentaram suas palavras, a primeira é participação no debate inicial, o segundo é um depoimento dos educandos após quatro aulas de leitura e os dois últimos são um questionário estruturado e um texto criativo. A turma contava com um total de 18 educandos, no entanto nem todos elaboraram todas as atividades por isso o número é desigual. Apresentaremos a seguir reflexões sobre cada etapa da sequência didática.

\subsection{Debate inicial}

No debate, que durou duas aulas de 45 minutos, tomamos nota de algumas afirmações dos estudantes, mas apenas após o final, para não inibi-los. Ficou claro que a principal fonte de informações que os educandos têm é a televisão. À época, a principal notícia que lhes vinha à mente era um surto de ebola. Para eles esta era a imagem da África, surtos de doenças, epidemias diversas, fome generalizada, imigração, pobreza e, talvez a única imagem não 


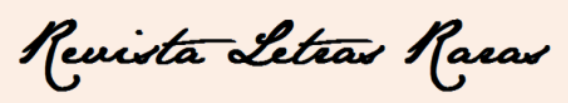

ISSN: 2317-2347 - Vol. 5, Ano 5, № 2 - 2016

ligada a um quadro negativo são os animais selvagens (leões, zebras, girafas, etc). A maioria afirmava que África seria um país, e não um continente, e não conseguia traçar paralelos entre a cultura brasileira e a africana. O quadro geral do debate mostrou o grupo com uma visão bastante estereotipada da cultura africana pela mídia televisiva.

\subsection{Depoimentos iniciais}

Após quatro aulas de leitura do livro Aya de Yopougon e seu prefácio (alguns estudantes levaram o livro para casa e adiantaram ou mesmo finalizaram a leitura), solicitamos às/aos educandos que escrevessem livremente sobre a experiência de leitura. Eles e elas estiveram livres para escrever aquilo que sentissem vontade, então eles/elas escreveram sobre a leitura em geral, sobre a leitura coletiva e também sobre o livro.

Nos depoimentos ${ }^{4}$ as/os estudantes puderam falar de qualquer aspecto da atividade que quisessem, aquilo que lhes fosse mais interessante. A extensão também era livre. Percebemos que a afetividade foi um tema frequente, para eles foi importante falar do gostar ou não da atividade e do livro. Nos depoimentos foram apontadas descobertas a respeito da África e também sobre similaridades entre a cultura marfinense mostrada no livro e a cultura brasileira, por exemplo "Este tipo de história é o que mais acontece no Brasil" (depoimento 1); "Essa história fala de um lugar da África, onde vivem muitas pessoas diferentes, conta sobre umas jovens amigas e suas famílias, cada um com seu jeito de pensar e agir" (depoimento 2); "Ele mostra que a África não é tudo o que pensamos" (depoimento 10) ou "hoje vejo a África de maneira diferente, alegre e divertida, não como eu pensava que só tinha vidas sofridas "(depoimento 14). Nota-se nesse momento que a leitura do texto literário se apresentava nos discursos dos educandos. Como demonstrado nesses trechos, vários já apontaram que suas visões sobre África haviam ou mudado, ou pelo menos se ampliado.

Por outro lado, notamos que aqueles que demonstravam ainda resistência com a leitura coletiva, se ativeram mais a esse aspecto afetivo de negação da atividade e não trataram do tema. Já os que relataram gostar da atividade, foram além e trataram também da temática da atividade. Por exemplo, o depoimento 13 em que não se trata da história: "Particularmente

\footnotetext{
${ }^{4}$ A íntegra dos depoimentos, questionários e textos criativos consta na monografia de arquivada na Universidade de Brasília. Quando necessário foram realizadas modificações no que se refere à norma padrão escrita.
} 


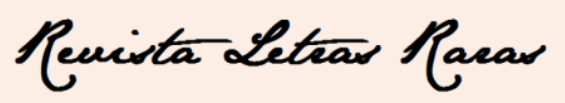

ISSN: 2317-2347 - Vol. 5, Ano 5, № 2 - 2016

gostei do livro, mas não gostei de ler coletivamente". Pudemos notar também que os depoimentos em que se apresenta uma avaliação negativa da atividade vinham ou de uma estudante que tem um nível de letramento mais avançado, e talvez não tivesse paciência para ouvir a leitura dos colegas ou dos estudantes muito tímidos. No entanto, mesmo com essa resistência o clima na sala de aula foi caloroso na maior parte das vezes e houve colaboração e ajuda mútua.

De maneira geral, os depoimentos foram positivos em relação à atividade, por exemplo, "Eu acho uma coisa legal, mas ao mesmo tempo chato e também é divertido." (depoimento 11), "Eu acho ler na sala de aula é bom, pois eu não tenho tempo para em casa. E o livro tem uma história boa, apesar eu ter lido todo ainda, mas até onde eu li eu gostei" (depoimento 12), "Gostei do jeito que o professor fez para que nós alunos lêssemos o livro de um jeito bem divertido para melhorar nossa leitura" (depoimento 16) e "Espero que a gente tenha mais leitura como essa na sala, eu gostei muito" (depoimento 17). Isso nos apontou que a escolha temática e metodológica era adequada e que valeria a pena continuar com a sequência didática tal qual planejada, principalmente, buscando envolver mais os estudantes com mais dificuldade de leitura ou mais tímidos.

\subsection{Questionários}

As perguntas apresentadas não tinham o objetivo de verificação da leitura ou interpretação do texto como se costuma fazer, até mesmo porque isso foi sendo realizado ao longo da leitura e de maneira diversas. De maneira geral, foi possível perceber avanço em relação à aceitação da leitura coletiva e dos jogos utilizados. Ao final da atividade os/as estudantes já se mostravam ávidos pela finalização da narrativa, por querer saber seu final e também ficaram curiosos por ler o segundo volume da história em quadrinhos, o que de fato alguns fizeram paralelamente.

Novamente, aparecem questões relacionadas à afetividade, do gostar ou não da atividade, porém ela não é da mesma natureza a respeito do livro, ou seja, mesmo que alguns afirmem não gostar da maneira com que foi feito, nenhum deles avaliou mal o livro lido. Isso nos mostra que, se havia resistência ou desconhecimento em relação ao tema "cultura africana" ele foi sendo aceito pelos/as estudantes ao longo do processo.

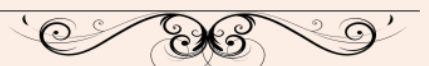




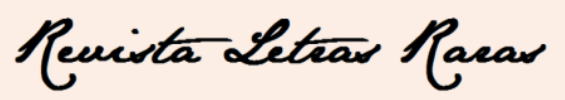

ISSN: 2317-2347 - Vol. 5, Ano 5, № 2 - 2016

Quanto à visão sobre a África e sua cultura e também quanto às relações dessa cultura com a Brasileira, eles foram praticamente unânimes a responder o questionário estruturado; com exceção do questionário 3 no qual o estudante afirma que não mudou sua visão sobre a África, pois continua "uma calamidade". Outros trataram do tema de maneira muito interessante e contundente, o que contribuiu para a validade da metodologia de intervenção proposta e no seu valor como fonte de material didático para cumprimento da Lei 10.639/2003 como podemos notar nos exemplos retirados das respostas a seguir: "as culturas, religiões, comidas, as danças, são bastante parecidas" (questionário 1); "Eu pensava que só tinha pobreza, mas tem muita cultura, diversão, achei parecido com o Brasil." (questionário 4); "Pra dizer a verdade a cultura da África é muito parecida com a cultura brasileira, e sim a minha visão da África mudou muito pois eu achava a África um lugar pobre e com muito tristeza e vi que não é bem assim." (questionário 5); "eu já tive um pouco de conhecimento através do livro o professor trouxe para nós alunos ler e conhecer uma África bem diferente" (questionário 7); “Que a África é um continente de grande diversidade cultural e é ligada à cultura brasileira. Não, não é parecida. Só é meio que parecida pelo fato das culturas, os costumes, etc... Na verdade não, porque não sei muito sobre a África." (questionário 8); "Aprendi que a África é normal como todas as cidades com coisas boas e ruins também. Sim, ela se parece com a brasileira. A minha visão mudou completamente." (questionário 10); “Aprendi algumas palavras que não conhecia como galeriano, maquis e alocôs. Parece um pouco com a cultura brasileira, pois eles gostam de festas e não passam fome do jeito que pensei. Minha visão mudou, porque eu percebi que eles podem ser divertidos como em qualquer lugar." (questionário 11) e "eu aprendi sobre a cultura africana que é uma cultura parecida com a do brasileiro. Minha visão sobre a África nunca foi de sofrimento." (questionário 14).

\subsection{Textos Criativos}

A última atividade proposta foi a elaboração de um texto narrativo que desse continuidade à história de um dos personagens do livro ou um desenho. O desenho foi proposto, pois o livro trabalha ao mesmo tempo com a linguagem verbal e não-verbal. Alguns estudantes fizeram um desenho mais simples junto com o texto ou colocaram uma figura. Nessa atividade, além da prática de escrita relacionada à disciplina de língua portuguesa,

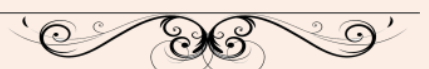




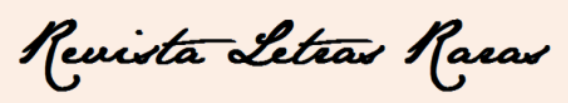

ISSN: 2317-2347 - Vol. 5, Ano 5, № 2 - 2016

tínhamos a intenção de verificar qual era a percepção das/dos estudantes em relação ao livro e como eles imaginariam sua continuação, isto é, que narrativas criariam a partir da leitura

Nos textos criativos, a grande maioria das/dos estudantes optou por finais "positivos" e relacionados à superação. Não havia a intenção de trabalhar esse aspecto, porém vários notaram como positiva a atitude de Aya, personagem título, em ser esforçada em relação aos estudos e também a estimular seus amigos a estudarem. Foi dessa forma, que apresentaram seus discursos, à esta altura, sobre uma re-elaboração de suas próprias narrativas e também de suas narrativas sobre África.

Nos textos criativos, temos finais criados pelos estudantes para a maioria dos personagens, o que também demonstra que eles estão atentos para uma atitude inclusiva de abarcar nas atividades personagens diversas. Partiu deles que cada um escolhesse um personagem, e não apenas as três personagens principais. Eles tiveram um protagonismo muito interessante nessa escolha. Por exemplo, o senhor Sissoko que fica muito feliz por ganhar um neto (texto criativo 1); o senhor Hyacinte que apesar de muito idoso continua muito requisitado para escrever jornais (texto criativo 2); Felicité que decide estudar e muda de vida (texto criativo 3); Mamadou que demonstra ser um jovem engajado na causa racial (texto criativo 5); Hervé que estuda e se torna um ótimo mecânico (texto criativo 7); Bintou que encontra um grande amor (texto criativo 8); Adjoua que se separa mas consegue trabalhar e constituir nova família (texto criativo 9) e Aya que vence todas as adversidades e se torna uma médica muito famosa e vem trabalhar no Brasil (texto criativo 12).

Nessa atividade, não foi possível notar se os educandos partiram para a escrita das vidas de personagens africanos de maneira naturalizada, possivelmente pela familiaridade que foram tomando com os personagens durante a leitura. De certa forma, acreditamos que houve a superação da barreira cultural e aceitação da diferença nessa intervenção. Tanto no desenho, quanto no texto criativo 5, é possível notar engajamento do estudante que procurou retratar um jovem trabalhador, que reflete sua condição de vida e sua cor, por exemplo, quando fala do uso do cabelo Black Power.

A opção por criar histórias de superação também pode estar relacionada às próprias histórias de vida dos estudantes, que apresentam, de maneira geral, muitas adversidades. Mas também é possível ver nessa escolha como a leitura da obra estimulou ou mesmo permitiu uma releitura e ressiginifcação sobre a África, de um continente em miséria, para um 


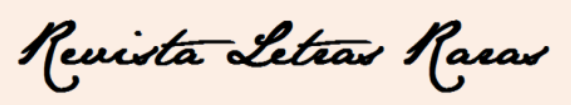

ISSN: 2317-2347 - Vol. 5, Ano 5, № 2 - 2016

continente de diversidade cultural e muitas afinidades com a cultura brasileira, não por acaso, pois é uma de nossas fontes.

\section{Conclusão}

A leitura coletiva da obra Aya de Yopougon se mostrou muito profícua, de maneira geral. Nela, ficou claro ser plenamente possível o cumprimento nas aulas de Língua Portuguesa do Ensino Fundamental, da Lei $n^{\circ}$ 10.639/2003 que dispõe sobre a obrigatoriedade do estudo da História da África e dos Africanos de maneira ampla nas escolas, especialmente por meio da educação artística, literatura e história. No nosso caso, a literatura, na forma de um livro em quadrinhos se mostrou um instrumento muito útil e valoroso para discussão e reflexão a respeito de novas leituras da cultura africana.

Verificamos assim, que o principal objetivo da pesquisa foi alcançado, em relação ao cumprimento da lei, no entanto, sabemos que a sensibilização pela literatura extrapola o simples atendimento de uma lei. Em relação à conscientização e formação de identidade notamos nos depoimentos, questionários e textos criativos, além da observação em sala de aula, um princípio de envolvimento que mostrou na identificação com a cultura africana, quando elas/eles relatam notar similaridades com o Brasil e também na resposta que deram afirmando que suas visões sobre África mudaram em relação ao início da atividade. A busca de leituras menos convencionais, apesar de incomodar alguns estudantes no início, foi bem aceita e teve os objetivos esperados alcançados, promovendo mais prazer na leitura, melhora no desempenho e desinibição. Talvez seja possível afirmar que as/os estudantes, agora, têm elementos para início de um engajamento na luta contra o racismo no Brasil, pois "lêem" a África de uma maneira diferente.

A atividade poderia certamente ser adotada em outras escolas e em outras turmas fazendo-se adaptações se necessário. Os resultados mostram que os estudantes estão abertos a ouvir e refletir sobre a cultura africana quando trabalhamos com um suporte literário e, portanto, o trabalho com sequências didáticas que tenham como base a diversidade cultural e tomem por apoio outras histórias em quadrinhos da temática seriam interessantes. Outros gêneros também poderiam ser adotados, como o cinema, canções, romances, contos e poesias, dentre outros. 


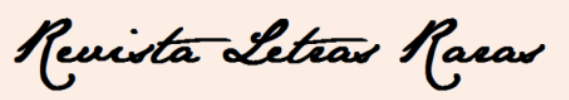

ISSN: 2317-2347 - Vol. 5, Ano 5, № 2 - 2016

\section{Referências}

ABOUET, Marguerite.; OUBRERIE, Clément (ilustrações). Aya de Yopougon Porto Alegre: L\&PM Editores, 2009, p. 106. Julia da Rosa Simões (Tradução)

AMORIM, Galeno (org.) Retratos da Leitura no Brasil. São Paulo: Imprensa Oficial/Instituto Pró-Livro, 2008.

BENVENUTI, Juçara. O dueto leitura e literatura na educação de jovens e adultos. Porto Alegre: Editora Mediação, 2012.

BRASIL. Lei $N^{o}$ 10.639, de 9 de janeiro de 2003. Disponível em $:<<$ http://www.planalto.gov.br/ccivil_03/leis/2003/L10.639.htm〉> acessado em 10/10/2015.

CANDIDO, Antonio. Na sala de aula. Caderno de Análise literária. São Paulo: Editora Ática, 1985.

CANDIDO, Antonio. O direito a literatura; In: Vários Escritos. São Paulo: Duas Cidades, 1995.

COMPAGNON, Antoine. Literatura pra quê?? Belo Horizonte: Editora UFMG, 2009

CANEN, Ana. Refletindo sobre identidade negra e currículo nas escolas brasileiras: contribuições do multiculturalismo. Revista Série-Estudos nº15. 2013.

COSSON, Rildo. Círculos de Leitura e Letramento Literário. São Paulo: Editora Contexto, 2014a.

COSSON, Rildo. Letramento Literário: teoria e prática. 2a edição. São Paulo: Editora Contexto, 2014b.

DIAS, Lucimar Rosa. Quantos passos já foram dados?A questão de raça nas leis educacionais. Da LDB de 1961 a Lei 10.639. História da Educação do Negro e outras histórias. 49-62. 2005

DINIZ, Lígia Gonçalves. Entre o obrigatório e o proibido: a literatura e o leitor em livros didáticos de língua portuguesa para o Ensino Médio. Dissertação de Mestrado. Universidade de Brasília. 145p. 2012.

DOLZ, Joaquim; NOVERRAZ, Michèle \& SCHNEUWLY, Bernard. Sequências didáticas para o oral e a escrita: apresentação de um procedimento. In: SCHNEUWLY, Bernard; DOLZ, Joaquim et all. Gêneros orais e escritos na escola. Campinas: Mercado das Letras, 2004.

FERNANDES, José Ricardo Oriá. Ensino de história e diversidade cultural: desafios e possibilidades. Cad. Cedes, Campinas, vol. 25, n. 67, p. 378-388, set./dez. 2005

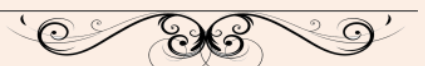




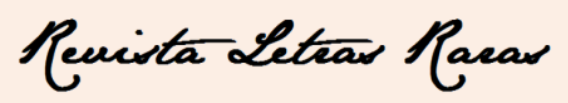

ISSN: 2317-2347 - Vol. 5, Ano 5, № 2 - 2016

FREIRE, Paulo. A importância do ato de ler: em três artigos que se completam. 51 adição. São Paulo; Editora Cortez. 2011.

KASTRUP, Virgínia. O devir-consciente em rodas de poesia. Revista do Departamento de Psicologia, UFF, v. 17. pp. 45-60. 2005

MANGUENEAU, Dominique. Discurso literário. Tradutor Adail Sobral. São Paulo: Contexto, 2006.

MORIN, Edgar. Os sete saberes necessários à educação do futuro. Tradução Catarina Eleonora F. da Silva e Jeanne Sawaya. $2^{a}$ Edição. São Paulo: Editora Cortez, 2012.

NASCIMENTO, Wanderson Flor do; DELMONDEZ, Polianne. Sujeitos da Diversidade. Curso de especialização em educação em e para os direitos humanos, no contexto da diversidade cultural. 2014.

OLIVA, Anderson Ribeiro. A História da África nos bancos escolares. Representações e imprecisões na literatura didática. Estudos Afro-Asiáticos, Ano 25, n 3, 2003, pp. 421-461

OLIVIEIRA, Luiz Fernandes; CANDAU, Vera Maria Ferrão. Pedagogia decolonial e educação antirracista e intercultural no Brasil. Educação em Revista. Belo Horizonte. v.26, n.01, p.15-40, abr.2010.

REIS, Maria da Gloria Magalhães dos. O texto teatral e o jogo dramático no ensino de francês língua estrangeira. 2008. Tese (Doutorado em Língua e Literatura Francesa) Faculdade de Filosofia, Letras e Ciências Humanas, Universidade de São Paulo, São Paulo, 2008. Disponível em: <http://www.teses.usp.br/teses/disponiveis/8/8146/tde-02122008171004/>. Acesso em: 10/06/2015.

ROSEMBERG, Fúlvia; BAZILLI, Chirley; SILVA, Paulo Vinícius Baptista. Racismo em livros didáticos brasileiros e seu combate: uma revisão de literatura. Educação e Pesquisa, São Paulo, v.29, n.1, p. 125-146, jan./jun. 2003

SANTOS, Vera Lúcia Bertoni; SPRITZER. Teatro com jovens e adultos. Porto Alegre: Editora Mediação, 2012.

ZILBERMAN, Regina. A leitura e o ensino da literatura. Democracia, educação e leitura. A escolha do texto. Segundo grau, vestibular e literatura. $2^{\text {a }}$ Edição. São Paulo: Editora Contexto, 1991. 